\title{
Worm cast in starring role for Nobel prize
}

Erika Check, Washington

A humble nematode has wormed its way into the affections of the scientific community and helped to secure this year's Nobel Prize in Physiology or Medicine.

The award goes to three biologists whose work on the model organism Caenorhabditis elegans has yielded insights and spin-offs in such diverse fields as cancer research and modern genomics.

South African-born molecular biologist Sydney Brenner, president of the Molecular Sciences Institute in Berkeley, California, will share the US\$1.1 million prize with John Sulston of the Sanger Institute in Cambridge, UK, and American Robert Horvitz of the Massachusetts Institute of Technology.

"This award is fantastic and welldeserved," says Robert Waterston, director of the Genome Sequencing Center at Washington University in St Louis. "It's not only a tribute to the investigators, but also to the power of the worm."

Brenner started the field of C. elegans biology in the 1960s. He had already made a name for himself as a founding father of molecular biology and wanted to concentrate on the development of the nervous system. So he began looking for a model system that was
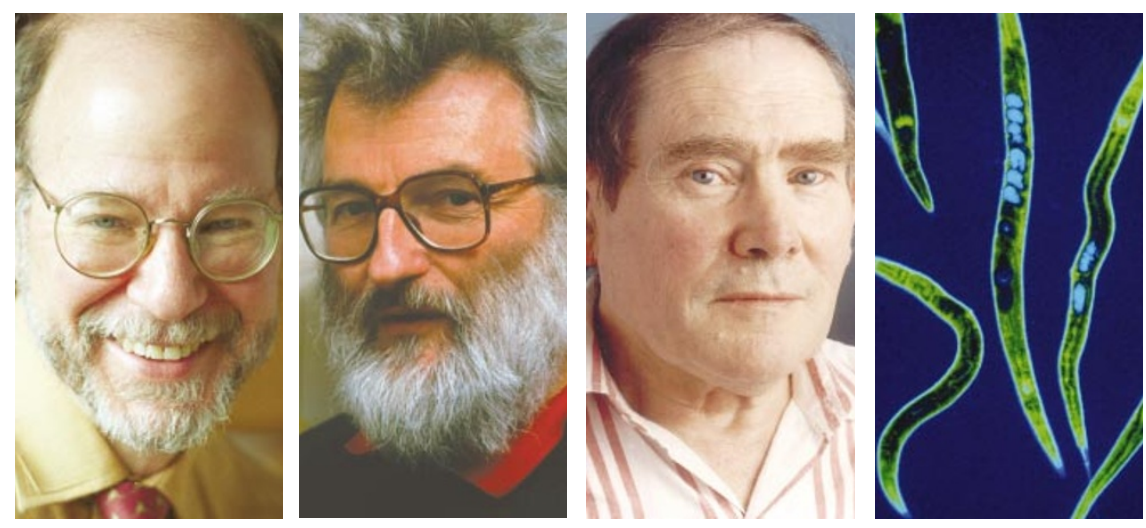

Developing a theme: (from left) Robert Horvitz, John Sulston and Sydney Brenner have won the 2002 physiology Nobel for their work on the biology of the nematode Caenorhabditis elegans.

simpler than the familiar fruitfly, but more complex than bacteria. He chose the nematode because of its short life cycle, genetic simplicity and tiny size — less than $1 \mathrm{~mm}$ long.

"We wanted to find a good experimental organism that people could study, and it has proved to be the right one," Brenner says. "What gives me the greatest pleasure is that so many people are working on this system now. When I meet scientists who are my 'great-greatgreat-grandchildren', it's very satisfying."
Sulston was one of Brenner's earliest students. During the early 1970s, he undertook the 'lineage project', in which he spent hours each day staring through a microscope at dividing C. elegans cells. Finally, in 1977, he published a complete map of how one fertilized egg gave rise to the 959 cells of the adult worm (J. E. Sulston and H. R. Horvitz Dev. Biol. 56, 110-156; 1977).

Along the way, Sulston made several crucial observations, including the recognition

\section{Universal view nets award for cosmic sleuths}

\section{Philip Ball, London}

Three pioneers who together opened a new window on the Universe have this year been rewarded with the Nobel physics prize.

Raymond Davis of the University of Pennsylvania in Philadelphia and Masatoshi Koshiba of the University of Tokyo share half the prize for developing techniques to detect the dauntingly elusive subatomic particles called cosmic neutrinos.

The other half of the award goes to Riccardo Giacconi for his role in building the first instrument for detecting X-rays from cosmic sources. Giacconi is now president of Associated Universities Incorporated, a Washington-based consortium that runs the National Radio Astronomy Observatory for the US National Science Foundation.

Davis set up an audacious experiment in the 1960s to detect neutrinos coming from the Sun. Solar theories had predicted that nuclear fusion reactions at the Sun's heart would generate vast numbers of neutrinos. But the particles rarely interact with matter, so it was unclear whether they could be detected.

To catch the solar neutrinos, Davis directed the construction of a detector at the Homestake gold mine in South Dakota, where a tank was filled with 615 tonnes of the

cleaning fluid tetrachloroethylene. He calculated that a tiny proportion of the neutrinos would have enough energy to collide with chlorine atoms in the fluid, creating argon atoms in the process. About 20 argon atoms were expected to be created every month, and Davis devised a method of extracting them by pumping helium gas through the liquid. By the time it closed in 1994, the experiment had detected about 2,000 argon atoms .
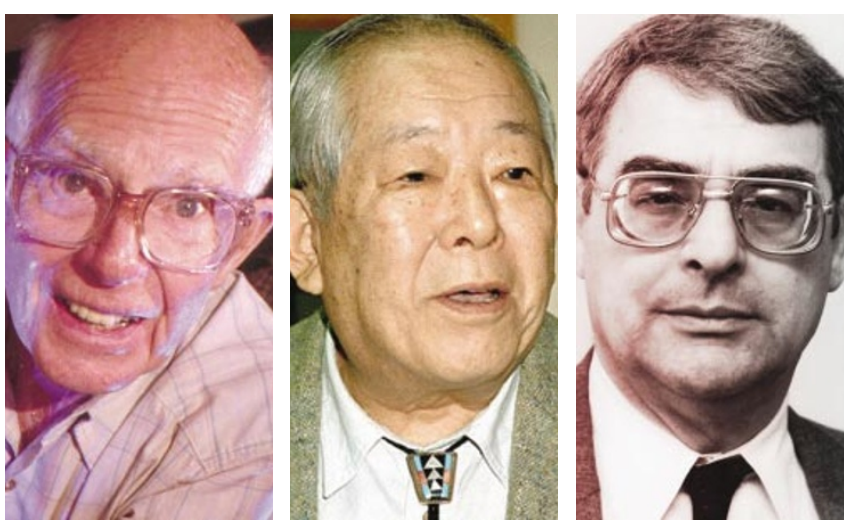

Out of this world: winners of this year's physics Nobel, (from left) Raymond Davis, Masatoshi Koshiba and Riccardo Giacconi.

Koshiba followed up this work in the 1980s, leading a team that built a neutrino detector known as Kamiokande. Housed in a mine roughly 240 kilometres northwest of Tokyo, Kamiokande monitored the light produced by neutrinos when they collided with water molecules, allowing it to identify when the particles arrived and which direction they were moving in. Koshiba's team showed conclusively that the Sun emits neutrinos.

In February 1987, the group also detected a neutrino burst from a supernova explosion in a neighbouring galaxy, showing that neutrino detectors could be used to study distant astronomical objects.

Koshiba's award is the third to go to Japan in as many years, keeping the country on track for the government's stated aim, set out in 2000, to try to win 30 Nobel prizes within 50 years. "My dream now is that one of my students can also get a Nobel prize," says Koshiba.

Giacconi began working on X-ray astron- 
that cells die in a repetitive pattern during normal animal development. He also discovered the first gene mutation that disrupted this process of 'programmed cell death'.

"I just loved watching the cells. It's a beautiful thing to do and a challenge in the jigsaw-puzzling sense to get it all," he says.

Horvitz picked up from Sulston's work on programmed cell death in the mid1970s. In 1986, he published a description of the first genes known to cause cell death - ced-3 and ced-4 (H. M. Ellis and H. R. Horvitz Cell 44, 817-829; 1986). He then proved that humans have a gene similar to ced-3, and showed that programmed cell death occurs through similar pathways in diverse life-forms, including humans.

Some scientists also see a larger significance to this year's Nobel, especially when combined with the 1995 Nobel for work in the fruitfly and the 2001 prize, which rewarded groundbreaking work in yeast.

"These awards are a recognition that you can make major advances in medicine by studying genetically tractable model organisms," says Gerald Rubin, a vicepresident at the Howard Hughes Medical Institute in Chevy Chase, Maryland. Additional reporting by Declan Butler.

omy in the late 1950s and helped to launch a field that has transformed our view of the Universe. Previously, astronomers had relied on optical, infrared and radio frequencies, but X-rays revealed violent astrophysical processes that no one had expected. "X-rays show us the extreme end of things," says Martin Ward of the University of Leicester, UK. Giacconi's award is "very well deserved for half a century of work in this area", he adds.

X-rays are absorbed by the Earth's atmosphere, so Giacconi's team developed instruments to detect them from rockets. Their initial aim was to see whether solar radiation caused X-ray emission from the Moon, but once beyond the atmosphere, their detector revealed other X-ray sources such as that in the constellation of Scorpius.

Strikingly, all three prizewinners have been recognized largely for their work on instrumentation - an acknowledgement, perhaps, that many questions in highenergy astrophysics cannot even be framed until observational methods exist.

Additional reporting by David Cyranoski.

The Nobel chemistry prize was announced

after Nature went to press. For coverage see www.nature.com/nature

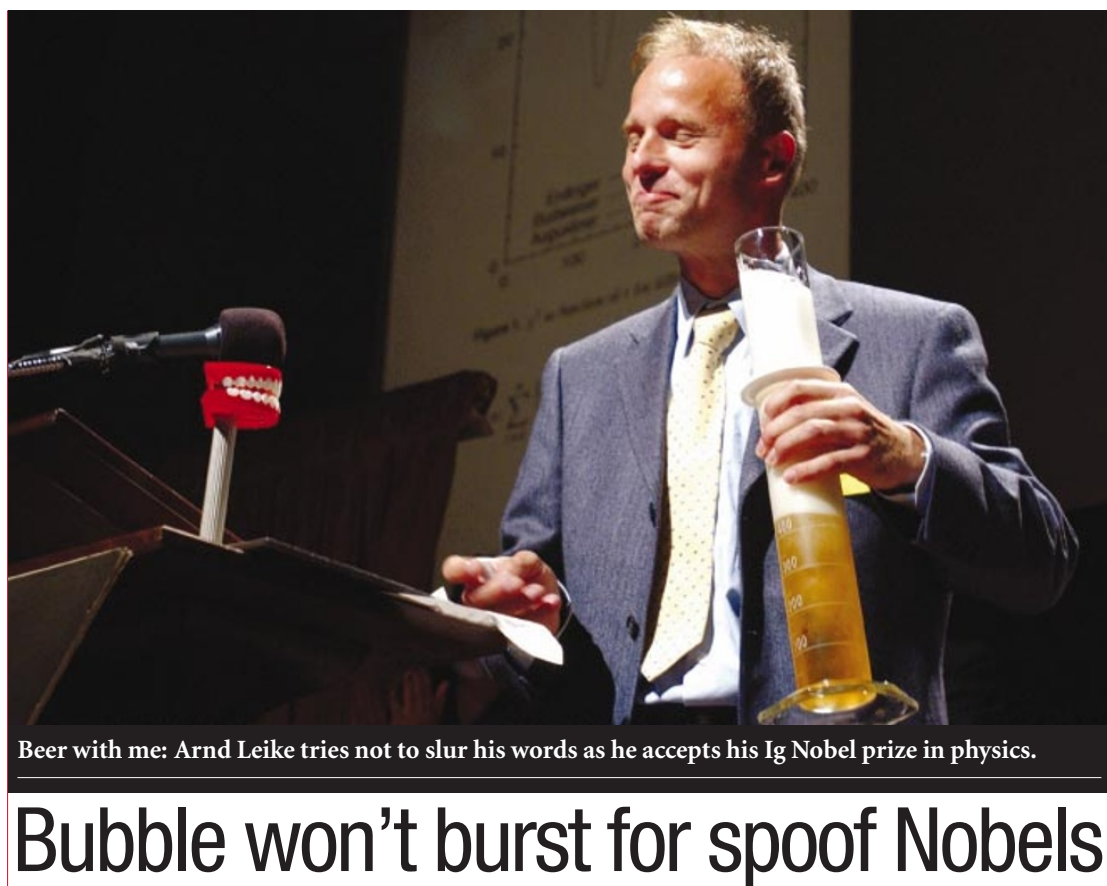

Steve Nadis, Boston

The conversation last Thursday in a pub near Harvard University was about beer but the discourse was perhaps a tad more elevated than the usual drunken banter.

For his work on the exponential decay of beer froth, Munich University physicist Arnd Leike was due to receive the 2002 Ig Nobel prize in physics. His companion that evening was Harvard chemist Dudley Herschbach, a Nobel laureate.

Herschbach pointed out that small beer bubbles disappear first, in the same way that small black holes evaporate faster than big ones. "There's something cosmic going on here," he said. The two then strolled to the nearby Sanders Theatre for the twelfth annual awards ceremony of the Ig Nobels

- Harvard's enduringly popular spoof on the real Nobel prize awards.

"Every winner was chosen for work that first makes people laugh and then makes people think," explains the event's organizer, Marc Abrahams.

This year's ceremony featured the world premiere of The Jargon Opera, 'a jargonfree mini-opera in four acts', gamely featuring Nobel laureates Herschbach, William Lipscomb and Richard Roberts.

David King, chief scientific adviser to the UK government, was also there. His appearance may have healed a rift that opened in 1996 when his predecessor Bob May warned that the Igs risked damaging science by ridiculing and trivializing worthy work (see Nature 383, 291; 1996). "I don't want to be critical of Bob, but I think this is all in good fun," King says.

King was personally able to congratulate his countryman Chris McManus of
University College London, who captured the medicine prize for a 1976 Nature paper, "Scrotal asymmetry in man and in ancient sculpture".

Navel-gazing brought a prize for Karl Kruszelnicki of the University of Sydney. His survey of the qualities of human belly-button fluff earned him the interdisciplinary research prize. And Charles Paxton of the University of St Andrews, UK, accepted the biology prize for a report he co-authored claiming to have found that sexual arousal in ostriches is enhanced by the presence of humans.

Vicki Silvers of the University of NevadaReno and David Kreiner of Central Missouri State University shared the literature prize for their study, "The effects of pre-existing inappropriate highlighting on reading comprehension". The message of their paper, said Kreiner, is "don't buy a textbook that has been highlighted by an idiot".

Theo Gray of Wolfram Research won the chemistry prize for creating a threedimensional periodic table of the elements that also serves as a coffee table. During his acceptance speech, Gray apologized to his parents for dropping out of graduate school, noting that "this is as close to academic distinction as you're going to get out of me".

Leike toasted the audience and sipped beer from a graduated cylinder. "I hope my paper will help get people interested in science," he later told Nature.

Herschbach agrees with the sentiment. "The whole reason for taking part in something like the Igs is to convey the message that scientists are really kids at play," he says. 